\title{
Experiences from the Series of International Robotics Workshops
}

\author{
Richard Balogh $^{1, *}$, Grzegorz Granosik $^{2}$, Valery Kasyanik $^{3}$, David Obdrzalek ${ }^{4}$ \\ ${ }^{1}$ Faculty of Electrical Engineering and Computer Science, Slovak University of Technology in Bratislava, Slovakia \\ ${ }^{2}$ Institute of Automatic Control, Lodz University of Technology, Poland \\ ${ }^{3}$ Department of Intelligent Information Technologies, Brest State Technical University, Belarus \\ ${ }^{4}$ Faculty of Mathematics and Physics, Charles University in Prague, Czech Republic
}

Copyright $\bigcirc 2016$ by authors, all rights reserved. Authors agree that this article remains permanently open access under the terms of the Creative Commons Attribution License 4.0 International License

\begin{abstract}
In this paper we summarize our experiences with the series of educational robotics workshops organized for a group of students from four schools in four countries. Brief description of the activities, their results and evaluation are presented.
\end{abstract}

Keywords Robotics Education, Robotics Contest, Robotics Workshop

\section{Introduction}

Robotics became recently one of the best tools for training students at various engineering courses. Why is robotics so popular in the educational environment?

One of the main reasons is its multidisciplinary approach. Robotics fits to a wide range of disciplines starting from mechanics, electronics, control engineering and programming to mathematics, physics and even the biology. Robotics also offers a concrete, visible results and attractive modern applications. It uses intelligent algorithms, which may be tested on very complex robotic systems.

As Mataric [1] points out, although robotics seems to be an excellent educational tool, the pedagogy of teaching with robotics is still in its infancy. The main learning theory, which has been perceived as useful for robotics education, was termed constructionism by Papert [2] and it is often used and mentioned [3],[4]. Several attempts have been made to introduce robotics not only at the university level, but also in lower levels, even from kindergartens [5] up to secondary schools [6]. Robotics education steps out of the schools and it is trying to attract children in a free-time clubs, summer camps or museums [7]. An in-depth overview of European educational activities in the robotics field can be found in [8].

Although robotics is suitable education tool for every age group [1], methods used to employ robotics in education are very different - they depend not only on the discipline but also on the country.

Visegrad Robotics Workshop (VRW) was a one-year project devoted to identify and present these differences, to share some methods we are using to teach and some ideas we are using to popularize robotics in four countries: Slovakia, Poland, Belarus, and Czech Republic. Universities involved in this project organized seminars or conferences, showed some specific features in teaching and laboratory work. Exchanging knowledge, experience, problems, and even missions was very important and inspiring. International group stimulated new solutions during workshops based on various backgrounds of participants. In addition, each organization conducted its own robotics competition. To implement the idea of VRW, the authors have joined forces in a standard grant at the International Visegrad Fund [9].

The Visegrad Group, also called the Visegrad Four, or V4 is an alliance of four Central European states- Czech Republic, Hungary, Poland and Slovakia - for the purposes of furthering their European integration as well as advancing their military, economic and energy cooperation with one another. The purpose of the International Visegrad Fund is to facilitate and promote the development of closer cooperation among citizens and institutions in the region and other countries, especially in the Eastern Partnership regions [9].

\subsection{Goals of Visegrad Robotics Workshops}

Visegrad Robotics Workshop [10] was composed of four events organized in four partner cities: Bratislava (Slovakia), Prague (Czech Republic), Łódź (Poland) and Brest (Belarus). Each event was three-fold and contained:

1. workshop, giving hands-on experience for participants,

2. lectures or conference being an educational part and 
3. robotic competition providing comparison of achieve-ments, hands-on experience and entertainment.

\section{Four Cities - Four Experiences}

Mixed group of students from all four participating universities (4 students from Belarus, 4 from Czech Republic, 3 from Slovakia and 4 from Poland) was created. The students already attended basic courses at their home universities, but they lack of any practical experiences. We assumed not to repeat the basic courses but to build some additional knowledge and necessary skills based on hands-on experiences.

\subsection{Workshop in Bratislava}

The 13th annual international robotic contest Istrobot [11] organized by Slovak University of Technology in Bratislava (STU) and Robotika.SK was the first event of VRW. This dynamic competition lasted whole day and was located in the premises of the Faculty of Electrical Engineering and Information Technology. Visitors could see over 60 robots in four official categories and on display in the corridors of the faculty. More than 500 spectators came to see various robots competing on the scene and presented all around. The competition was a great start and motivation for students in our mixed group. They were expecting to do something similar in following days.

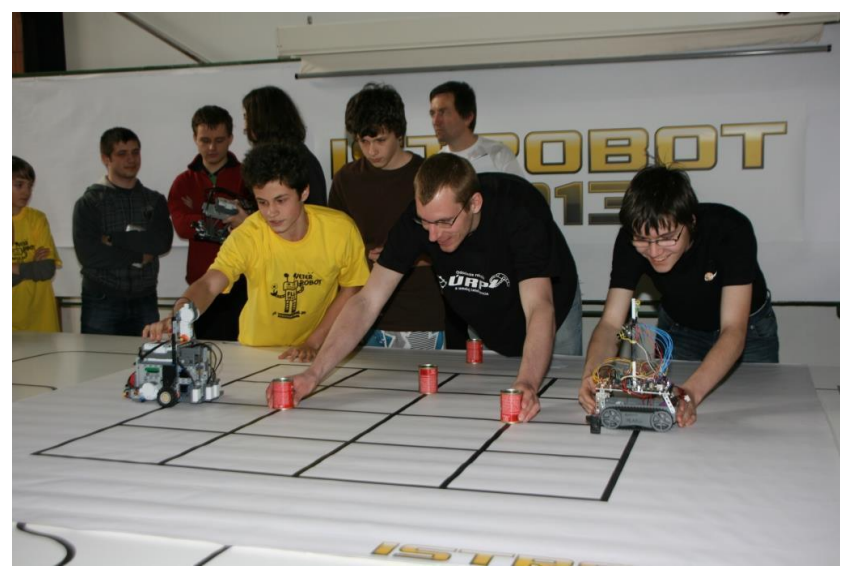

Figure 1. International robotics contest Istrobot in Bratislava.

The next day the study part of the workshop began. Students could listen to interesting lectures and had hands-on workshops in the laboratories of the Institute of Control and Industrial Informatics. The topics of presentations are listed in the evaluation table (see Tab. 1). Besides the lectures, students had the laboratory tour and hands-on workshop with Acrob robots [12]. The detailed explanations on the objectives and experiments were provided. Part of the workshop was also an excursion to the ME-Inspection Company. Company sensors production and live inspection systems were presented. Evaluation of the activities based on questionnaires from the participants is summarized in Tab 1. Students were highly motivated and were able to grasp concepts very quickly. Within an hour they were able to program the Acrob robots within the Arduino environment. Robots were able to perform a simple line-following with an obstacle avoidance.

Table. 1 Evaluation of the first workshop in Bratislava. Marking is based on school grading system: 1 - best / 5 - worst. Results are based on 13 valid responses.

\begin{tabular}{|c|c|c|c|c|}
\hline & Activity & Avg & Min & Max \\
\hline 1 & Istrobot robotic contest & 1,31 & 1 & 2,5 \\
\hline 2 & $\begin{array}{c}\text { A. Lúčny: Learn Objects } \\
\text { Representation }\end{array}$ & 1,46 & 1 & 3 \\
\hline 3 & P. Petrovič: AI Topics & 1,92 & 1 & 3 \\
\hline 4 & P. Hubinský: History of robotics & 2,12 & 1 & 5 \\
\hline 5 & Acrob workshop and training & 1,15 & 1 & 2 \\
\hline 6 & Laboratories excursion & 1,62 & 1 & 3 \\
\hline 7 & ME-Inspection excursion & 1,69 & 1 & 3 \\
\hline
\end{tabular}

\subsection{Workshop in Prague}

The next visit within the Visegrad Robotics Workshop began with the jubilee 10th robotics competition Czech Robotic Day [13]. It was co-organized by the Robonika association and Charles University in Prague and brought over 120 robots from six countries. Over 500 spectators visited this event and observed seven categories of competitions. Since the start in 2004, Charles University supports the event recognizing the values of joint theoretical and practical education. Therefore, the special workshop is an indivisible part of the event both for teams and public. It is dedicated to the exchange of experiences related to the construction of the robots starting in the competition. Intentionally, this workshop is organized always one day after the competition when the participants are still well aware of everything concerning their robots but they are already past the competition stress. The basic layout of the workshop is set as a series of presentations by individual teams participating in the contest with sufficient time margins for discussions.

At the workshop, teams discuss deep technical details and willingly answer many questions both from other participants, visiting students as well as public attending the workshop.

It has proven over the years that the impact of this workshop is manifold; participants share knowledge about all topics concerned (hardware, software, theory, algorithms, team management etc.) and set new contacts both on professional as well as social level. The presence of VRW participants was well accepted especially for the opportunity to discuss different curricula styles in their home institutions and possible future cooperation between them.

On the following days, the program consisted of lectures and hands-on exercises (see the Fig. 2 and the list in Tab. 2). 
Every day the morning was devoted to the lectures and the afternoons were reserved for practical hands-on robotic lab experience. These were implemented using a mobile robot MOB-2 (see Fig. 3) designed by David Obdržálek [14] for his curricula on software engineering and allowed for efficient testing of control algorithms. Although the participants did not have any experience with this particular platform, they were quickly able to exploit it and perform basic tasks in localization and control.

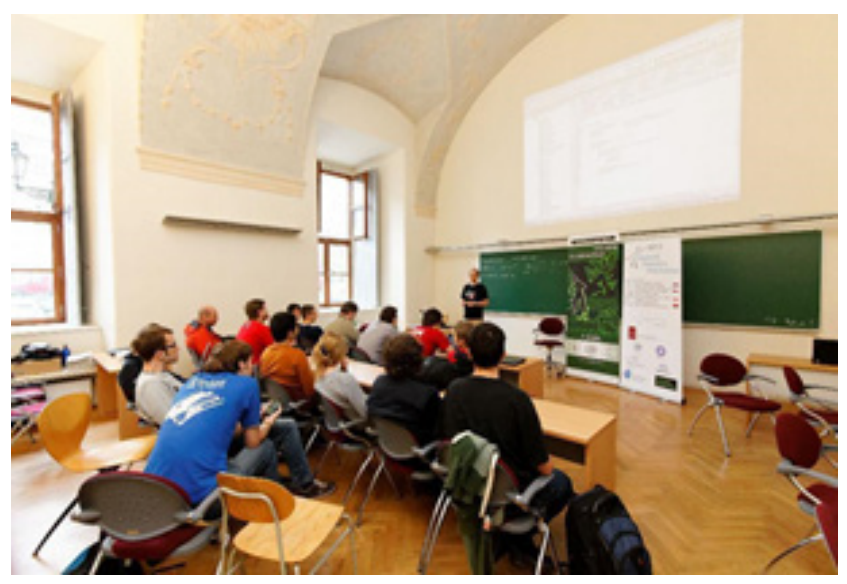

Figure 2. Workshop in Prague.

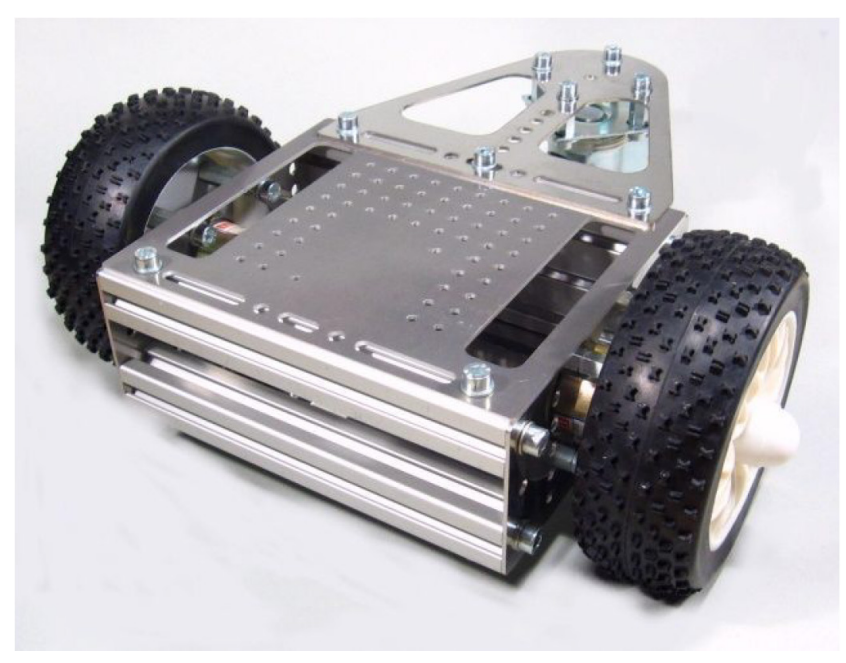

Figure 3. Mobile robot MOB-2 was used on workshop in Prague.

Table 2. List of activities on the second workshop in Prague

\begin{tabular}{|c|c|}
\hline & Activity \\
\hline 1 & Robotic Day - the contest \\
\hline 2 & T. Bureš: real-time scheduling. \\
\hline 3 & T. Plch: Artificial Intelligence and Decision Making \\
\hline 4 & A. Wilkie: Predictive Rendering. \\
\hline 5 & M. Vomlelová: Markov Decision Processes. \\
\hline 6 & Hands-on Laboratories \\
\hline
\end{tabular}

\subsection{Workshop in Łódź}

Robotix Week in Lódź started on 17. 11. 2013 with workshop about human-robot interfaces based on Android devices or other computers communicating via Bluetooth. The latest gadgets like smartphones, tablets or laptops are perfect for intuitive driving of the mobile robot, and if the robot is additionally equipped with a camera we can see on the screen images from the remote places where we had sent our scout to. Students have proposed different scenarios for small micromouse robots being controlled from mobile devices ${ }^{1}$. This Interactive Robotics Workshop was following five simple points:

1. Teacher explains how Processing and Arduino works.

2. Students work in groups, creating interface for human-robot interaction that solves some problem.

3. Students start with a prototype, then test, then make better prototype.

4. Students have to test their projects with different people (from same group and from other groups).

5. Successful project is the one in which no explanation is needed (and is fun).

The detailed description of this workshop and the whole philosophy behind it can be found in [15]. The next day brought a new experience - working with sets of LabVIEW Robotics Starter Kit [16] utilizing hardware and software from National Instruments - project partner of the Robotix Week. Students got familiar with LabVIEW graphical programming environment; worked with RealTime and FPGA based systems being brains of the mobile robots. Sixteen people participated in this workshop, most of them using LabVIEW for the very first time. During 5 hours of hand-on experience they have learned the general idea of graphical programming, the structure of the hierarchical control system of DaNI mobile robot (i.e. low level control of two motors, encoders and sonar, mid-level control of trajectory following, kinematics of unicycle, obstacle avoidance, and the user interface), and they made simple programs. Students started with direct control of motors from simple user interface, and then used relation between sensor and motors to safely stop the robot in the front of an obstacle. Then the students continue with the application to control mobile robot in the XY coordinate frame.

Next two days the students were involved in the $4^{\text {th }}$ International Conference on Robotics in Education (RiE 2013) [17] which hosted over 50 participants from 17 countries. Twenty two regular papers were presented in the sessions and we could see robot exhibition with LabVIEW Robotics, Kuka Agilus and the NAO Robot. Students were listening the presentations and even that some talks were too theoretical for them, interesting and useful facts were learned. For most of students, it was a first real scientific 
conference visited, so they consider it as a valuable experience.

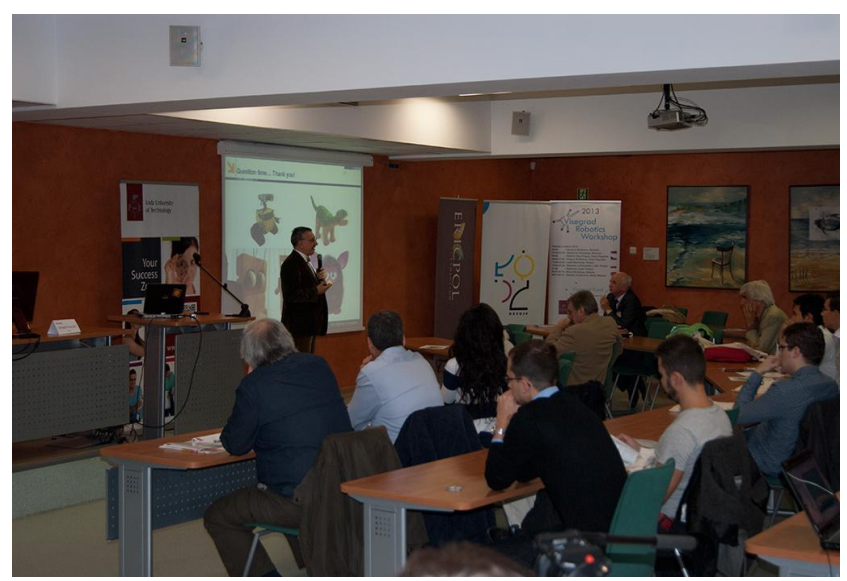

Figure 4. Prof. Andrea Bonarini’s plenary talk on RIE 2013.

On Saturday the sun came out and the inhabitants of Łódź (a few hundred people, mostly with kids) were able, for the first time in Poland, to see the struggles of autonomous mobile robots in the Poniatowski Park. Autonomous mobile robots had to travel from the ordered starting location to the ordered destination location using only paved routes available on the openstreet map of the area. There were four rounds during the contest with different start-end locations. Robots were starting simultaneously (Fig. 5) and should avoid obstacles (e.g. other robots) in front of them, and never stride to the grass area of park. Routing between start and final location had to be made autonomously, too. Robots had one hour to reach the goal. Robots were struggled not only with technical problems but also with environmental conditions: there was not much difference between paved and green parts of routs in the park, the sun shining through the trees confused vision systems, and leaves lying all over the places were nightmare for laser and vision sensors. Results of the Robotour competitions are shown in the Tab. 3 .

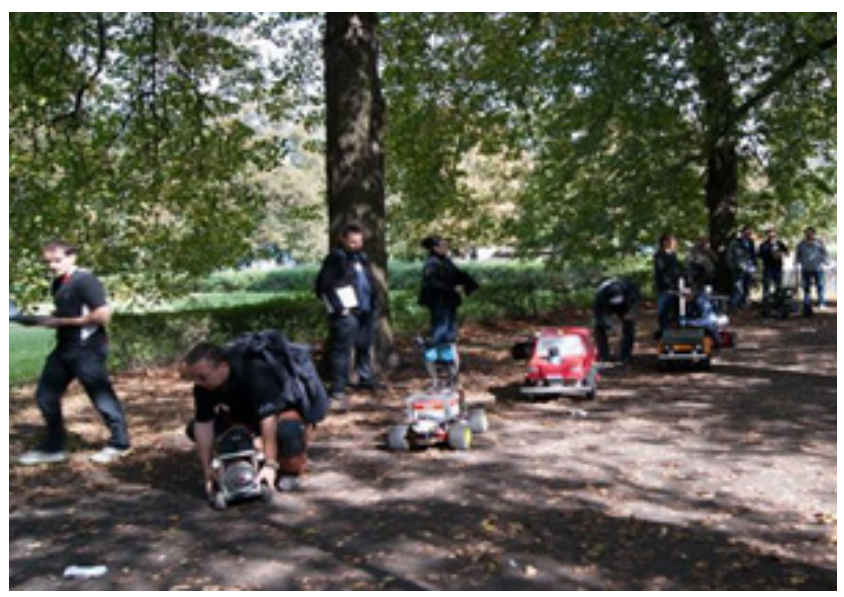

Figure 5. Robotour - an outdoor robot competition in Łódź.
Table 3. Results table of the Robotour contest

\begin{tabular}{|c|c|c|c|c|c|c|c|}
\hline Rank & Team & From & \multicolumn{4}{|c|}{ Rounds 1--4 } & Total \\
\hline 1. & ARBot & $\mathrm{CZ}$ & 0 & 505 & 384 & 172 & 1061 \\
\hline 2. & Roboauto Quido & $\mathrm{CZ}$ & 0 & 408 & 1 & 40 & 449 \\
\hline 3. & Radioklub Písek & $\mathrm{CZ}$ & 72 & 14 & 71 & 195 & 352 \\
\hline 4. & Short Circuits & $\mathrm{CZ}$ & 46 & 100 & 4 & 14 & 164 \\
\hline 5. & RoboFIT & $\mathrm{CZ}$ & 30 & 5 & 0 & 0 & 35 \\
\hline 6. & AutoLUT & $\mathrm{PL}$ & 5 & 0 & 0 & 18 & 23 \\
\hline 7. & Smelý Zajko & $\mathrm{SK}$ & 0 & 8 & 0 & 0 & 8 \\
\hline 8. & Plecharts & $\mathrm{CZ}$ & 0 & 0 & 0 & 0 & 0 \\
\hline
\end{tabular}

The Robotour contest [18] was brought to Łódź from the Czech Republic by Martin Dlouhý from the non-profit association Robonika. Eight robots of various sizes and constructions were designed to independently drive the distance of over 500 meters from the starting point to the target location determined by GPS coordinates. Although the participants of our workshop were not parts of the competing teams (but their teachers did), they were very curious and we found them often immersed in discussions with authors of the robots.

\subsection{Workshop in Brest}

The last meeting of the project took place in Brest and included the International Conference Robotics and Artificial Intelligence, Problems and Perspective (RAIPAP) [19], workshops and robot competition Roborace [20], all of them were organized by the Brest State Technical University.

Table 4. Activities in Brest workshop.

Marking is based on school grading system: 1 - best / 5 - worst.

\begin{tabular}{|c|c|c|c|c|}
\hline No. & Activities & Average & Min & Max \\
\hline 1 & Conference RAIPAP'13 & 2.33 & 1 & 4 \\
\hline 2 & Excursions & 1.5 & 1 & 5 \\
\hline 3 & Roborace Competition & 1.91 & 1 & 5 \\
\hline
\end{tabular}

Table 5. Voting of best activities.

Results are based on 13 valid responses.

\begin{tabular}{|c|c|c|}
\hline & Activities & No. of votes \\
\hline 1 & $\begin{array}{c}\text { A. Kabysh: Reinforcement learning in } \\
\text { Robotics }\end{array}$ & 6 \\
\hline 2 & $\begin{array}{c}\text { A. Imada: How can we make robot } \\
\text { navigation more intelligent? }\end{array}$ & 2 \\
\hline 3 & $\begin{array}{c}\text { V. Golovko: From neural networks to } \\
\text { intelligent systems: researches and } \\
\text { application }\end{array}$ & 10 \\
\hline A & POP-BOT Roborace Competition & 3 \\
\hline B & POP-BOT Reinforcement Learning & \\
\hline
\end{tabular}

Practical part of the workshop consisted of the workshop on robots programming using the machine learning tools 
(reinforced learning). Programs were tested on mobile robots Pop-Bot ${ }^{2}$ and using the RL-Glue environment [21]. Second workshop was devoted to the preparation of robots to compete in a special run during competition Roborace (see workshops voting in tables 4 and 5).

It is quite natural, that the conference, which was held for the first time, received the smallest evaluation. In the Belarus the robotics is still too young to organize serious conference.

Let us describe the Roborace competition in more details. The competition idea originates from the Formula One competition. It is very famous and hi-tech race and the Roborace competition took the best from it. The main challenge of the Roborace is to prepare the robot for dynamically changing environment on the track. Not only the track following is necessary, but also the other competing robots are part of the environment. The winner is the robot, which can pass the 25 laps in shortest time. Length of the single lap varies, but usually its length is $25-$ 30 meters, giving the total length of circa 625 meters. Students can build their own robots or they can use a pre-made platform. They are working in teams, usually consisting of two or three students: programmer, mechanic and electronic engineers. The competitions start with qualifications selecting the fastest robots for semifinals, where the 15 laps is required to race. Three best robots from each semifinal compete in finals. Winners usually drive total length up to $1000 \mathrm{~m}$.

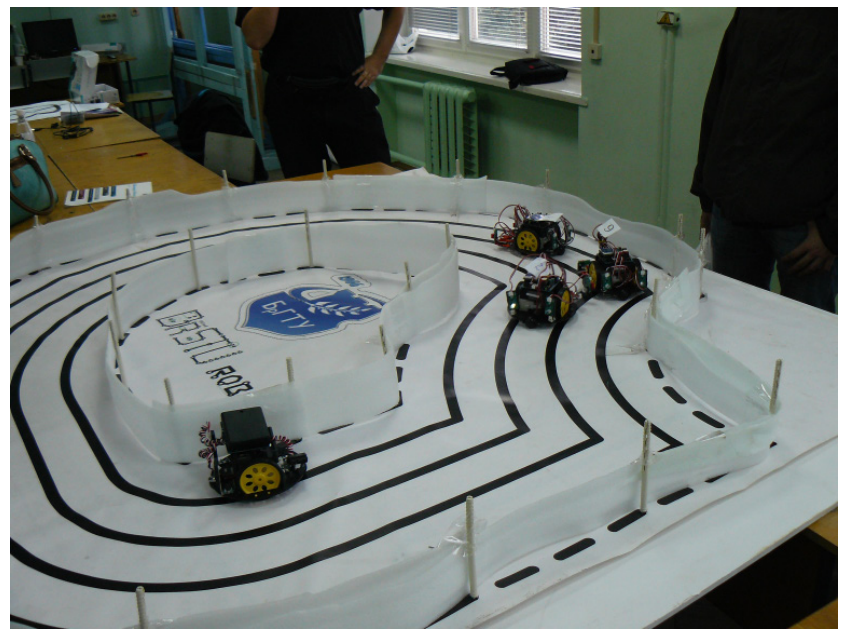

Figure 6. The Roborace competition in Brest - robots in action

Every track (see Fig.) has the walls and black lines which makes possible to use the various approaches to robot control. Beginners can use the strategy based on simple black line following algorithm, which is slow, but reliable. Advanced competitors are using infrared or ultrasonic range finders for adaptive and more complicated strategies. Six robots on the track create unpredictable dynamic environment, and the control algorithms has to cope with it.

2 https://www.sparkfun.com/products/retired/9501
During the race, the robots can overtake one another, but also to flip over, or to be stuck. It is allowed to pick the robot and move it to the pit stop and after repair put it to the start point again.

Power efficiency, strategies for overtaking, pit stops and sensor placement make Roborace a very good sandbox for experiments. Students and teachers are usually spending up to the 2-3 weeks per month for basic experiments and programming, to be prepared for real tests of their ideas on the track. Using the Roborace as a robotics teaching tool is very efficient, but it requires a really large amount of students' time. This is sometimes very difficult if not impossible to achieve. Often the additional problem with the teamwork appears and the teams have to learn it for the success in races.

Table 6. Results of mini-race for POP-BOT

\begin{tabular}{|c|c|c|}
\hline Team & Passed laps & Time [mm:ss] \\
\hline CrazyTeam & 3 & $02: 23.193$ \\
\hline Bisons & 3 & $02: 44.830$ \\
\hline Real_Rear_Wheel & 3 & $06: 32.793$ \\
\hline Kiborg & 3 & $07: 16.536$ \\
\hline Honnza_and_Przemek & 1 & $07: 03.322$ \\
\hline Stuff & 0 & $00: 00.000$ \\
\hline
\end{tabular}

\section{Professional's final}

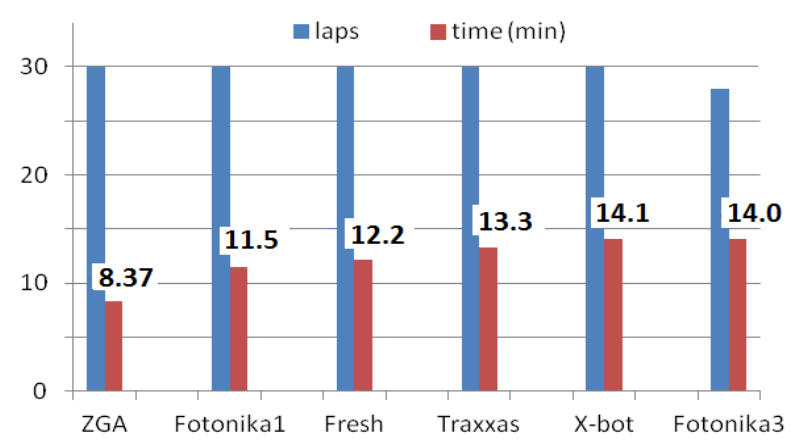

\section{Beginner's final}

- laps $\quad$ time $(\mathrm{min})$

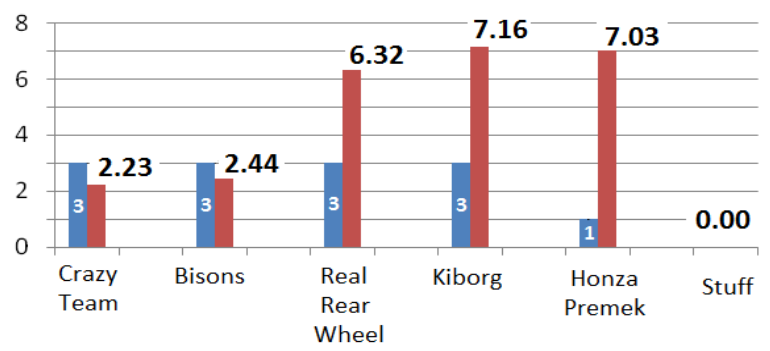

Figure 7. Comparison of the race results

During the of Brest VRW we want to see how good will be the mixed students teams from Slovakia, Czech Republic and Poland without preliminary experiences with this type of competition. With this question in mind, we organized the special mini-race with the three laps only and for the pre-made POP-BOT platforms. Results are summarized in the Tab 6 . We can see that four out of the six teams $(66.6 \%)$ 
were able to successfully finish all the three laps. Comparing the times achieved, we can see the very small difference between the first and second pairs of robots. This shows that even beginners coped with the task successfully and demonstrate very good motivation for the problem solving. For comparison, we provide also the results of both beginners and "professionals" (see Fig. 7). The main difference is in the higher time variations in beginners' class.

These results proved the idea that the Roborace is a very good robotics training method. In the future, we plan further improvements of the Roborace competition.

\section{Results of Workshops}

The main output of the project was a series of workshops that could help to launch new internationally connected activities. During four events we shared our knowledge and experience in teaching robotics and other high-tech related subjects (control theory, computer graphics, Android programming, artificial intelligence) and therefor e we have strengthened the scientific potential in participating organizations. Our face-to-face meetings proved to be much more effective than any kind of distant conversation and learning. Being in one place for a few days, faculty and students became aware of the local problems and learned new methods of teaching. We have continuously exchanged ideas, discussed new opportunities and further plans. We have prepared extended version of VRW involving more organizations from Eastern Partnership countries (Belarus and Ukraine), but unfortunately, mostly due to the safety issues, was not realized yet.

One of the examples how ideas were spread is the Ketchup House tournament. Until 2013 it was known only in Bratislava, during the VRW the Czech group was able to observe it and later bring all equipment necessary to organize the same competitions during event in Prague (see Fig. 8).

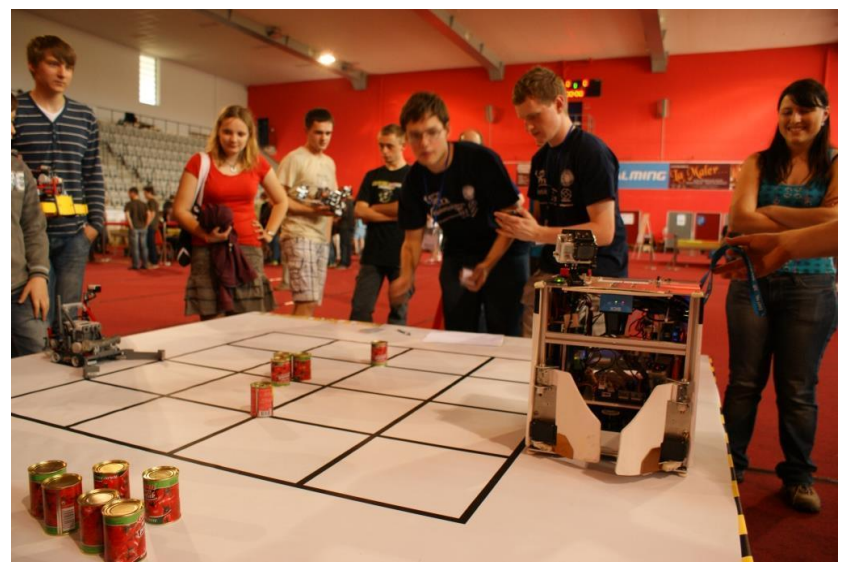

Figure 8. Ketchup House competition at the Czech Robotic Day (compare with the same competition on Fig. 1).

The Robotour contest (until 2013 organized in Czech
Republic, Slovakia and Austria) was brought to Poland as a part of Robotix Week (see Fig. 5). Similarly, International Conference on Robotics in Education started its travel beyond the original region: previous editions in Bratislava, Vienna and Prague were extended by holding it in Lodz and later continued in Italy 2014 and in Switzerland 2015. Last edition will be in April 2016 in Vienna.

This project was also the main motivation to organize International Conference on Robotics and Artificial Intelligence, Problems and perspective (RAIPAP) in Brest where we had the opportunity to listen to guests from Belarus, Ukraine and Russia.

New knowledge came also with the Roborace competition (see Fig. 6) - contest unknown in Visegrad countries, while extremely popular in Ukraine, Belarus and Russia. It was a very spectacular event with a dynamic course, which possibly will be adopted in other countries next year.

Brest Workshop had immediate results - participation in Roborace run - all students worked on the same robots and, therefore, control programs were the main issue showing seamless cooperation in mixed teams. As we expected, events in different countries encouraged students for mobility and gave positive results on social and personal level.

In total, almost 40 different persons from partner organizations attended workshops expanding their knowledge and experience; several hundred took part in conferences and competitions within the project.

\section{Discussion and Conclusion}

All four workshops brought new experiences and besides the immediate positive impact on the participants, also some new challenges and questions. All participants, teachers and students appreciated the work in international teams, practical workshops and contests. For the future there is a question how to include such method of education into the standard curricula at the host universities. It would be beneficial if such workshops are not occasional but standard part of the regular engineering education. Financial support is crucial; without it, probably no one would take part in this venture. Especially travel and accommodation costs are too high to be covered by students themselves.

Involving students into the standard scientific conference should be recommended. Whenever possible, conference organizers should open access to such events at least to the students of the hosting institution. Also the showing the best of the standard lectures should be at least time-to-time presented outside of the standard curricula.

Partners explored possibilities and resources of each university and organization, they also observed robotics contests not known before. Some of them are now used in the robotics competitions in the other countries, e.g. Bear Rescue, Ketchup House, and Roborace are present in Poland at Sumo Challenge Robotics Competitions since 2014 and are getting more and more interest. 


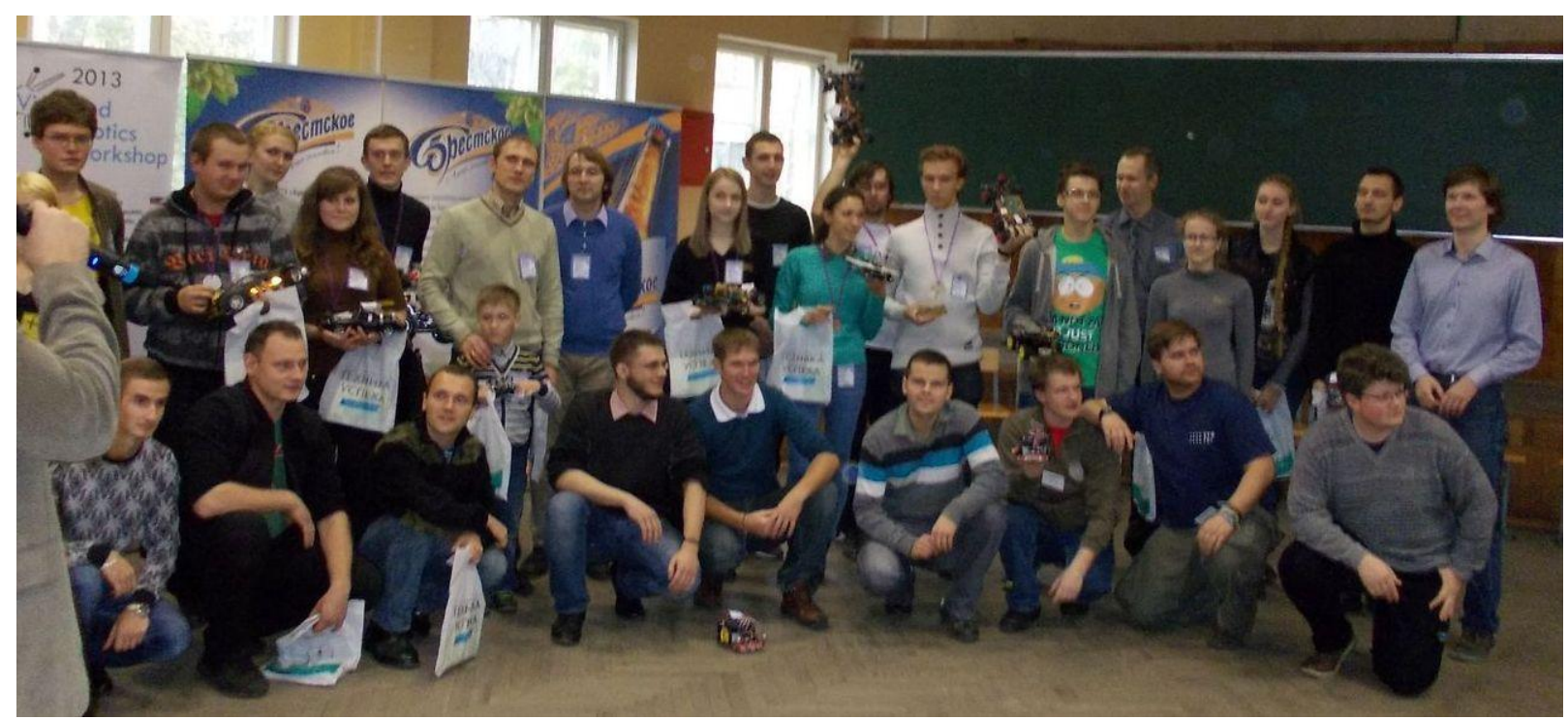

Figure 9. International cooperation - teams from Belarus, Slovakia, Poland and Czech Republic.

The other concept worth to be implemented in the future is an idea of a single study/research project being realized during several interconnected workshops performed in different countries.

\section{Acknowledgements}

This project was supported by International Visegrad Fund grant No. 21220294. Authors are also grateful for all the support of the hosting universities, students and the faculty involved in organization of described events. Publication of this paper was supported by the KEGA project No. 011STU-4/2015.

\section{REFERENCES}

[1] M. Mataric: Robotics Education for All Ages. Proceedings, AAAI Spring Symposium on Accessible, Hands-on AI and Robotics Education, Palo Alto, CA, Mar 22-24, 2004.

[2] S. Papert and I. Harel: Situating constructionism. Constructionism 36 (1991): 1-11. Available on-line: $<$ http://www.papert.org/articles/SituatingConstructionism.ht $\mathrm{ml}>$, retrieved 25. 01. 2016.

[3] D. Alimisis and Ch. Kynigos: Constructionism and Robotics in education. Teacher Education on Robotic-Enhanced Constructivist Pedagogical Methods (2009): 11-26.

[4] P. Petrovic: Constructionism Applied. Proc. of the 12th EuroLogo conference, Constructionism 2010, Paris.

[5] B. A. Maxwell and L. Meeden: Integrating robotics research with undergraduate education. Intelligent Systems and Their Applications, IEEE 15.6 (2000): 22-27.

[6] K. N. Stubbs et al.: STREAM: A Workshop on the Use of Robotics in K-12 STEM Education. Robotics \& Automation Magazine, IEEE 16.4 (2009): 17-19
[7] A. Polishuk et al.: The challenge of robotics education in science museums. Proceedings of the $4^{\text {th }}$ Knowledge Cities World Summit (2011): 319.

[8] A. Bredenfeld, A. Hofmann and G. Steinbauer: Robotics in education initiatives in Europe. Status, shortcomings and open questions. Workshop Proceedings of Intl. Conf. on Simulation, Modeling and Programming for Autonomous Robots (SIMPAR), 2010.

[9] International Visegrad Fund official webpage. Available on-line: <http://visegradfund.org/>, retrieved 25. 01. 2016

[10] Visegrad robotics workshop. The project information webpage. Available on-line: $<$ http://robotyka.p.lodz.pl/rie2013/index.p $\mathrm{hp} /$ visegrad-robotics $>$, retrieved 25. 01. 2016.

[11] Istrobot - an international robotic contest. Official webpages. Available on-line: <http://www.robotika.sk/contest/>, retrieved 25.01. 2016.

[12] R. Balogh: Acrob - an Educational Robotic Platform, AT\&P Journal Plus, November, 2010. Vol. 10(2), pp. 6-9.

[13] Czech Robotic Day. Official contest webpage. Available on-line: <http://www.roboticday.org $>$, retrieved 25. 01. 2016.

[14] D. Obdržálek: Robot Localization, PhD. Thesis, Charles University in Prague, 2012, pp. 58-62.

[15] I. Zubrycki and G. Granosik: Interactive Robotics Workshop, Proc. of 5th Int. Conf. Robotics in Education (RiE), ISBN 978-88-95872-06-3, pp. 60-67, Padova (Italy) July 18, 2014.

[16] LabVIEW Robotics Starter Kit. Official information webpage. Available on-line: $<$ http://sine.ni.com/nips/cds/view/p/lang/p 1/nid/ 208010>, retrieved 25. 01. 2016.

[17] Proceedings of the Robotics in Education (RiE) 2013 Conference. Lodz 2013. Available on-line: $<$ http://robotyka. p.lodz.pl/rie2013/>, retrieved 25. 01. 2016.

[18] Robotour - the outdoor delivery challenge. Contest official webpage. Available on-line: <http://robotika.cz/robotour>, retrieved 25.01.2016

[19] Proceedings of the Robotics and Artificial Intelligence Problems and perspective (RAIPAP'13) Conference. Brest 
State University, 2013. Available on-line: [21] Tanner, Brian, and Adam White. "RL-Glue: $<$ http://raipap.bstu.by/>, retrieved 25. 01.2016.

Language-independent software for reinforcement-learning experiments." The Journal of Machine Learning Research 10 (2009): 2133-2136.

[20] Roborace - Racing Robot's competition. Official web-pages. Available on-line: $<\mathrm{http}$ ://roborace.org/>, retrieved 25.01.20 16. 